\title{
Advanced Imaging and Receipt of Guideline Concordant Care in Women with Early Stage Breast Cancer
}

\author{
Elizabeth Trice Loggers, ${ }^{1}$ Diana S. M. Buist, ${ }^{2,3,4}$ Laura S. Gold, ${ }^{5}$ \\ Steven Zeliadt, ${ }^{4,6}$ Rachel Hunter Merrill, ${ }^{3}$ Ruth Etzioni, ${ }^{3,4}$ Scott D. Ramsey, ${ }^{3,5}$ \\ Sean D. Sullivan, ${ }^{3,4,5}$ and Larry Kessler ${ }^{4,5,6}$ \\ ${ }^{1}$ Clinical Research Division, Fred Hutchinson Cancer Research Center, Seattle, WA 98109, USA \\ ${ }^{2}$ Group Health Research Institute, Group Health Cooperative, Seattle, WA 98101, USA \\ ${ }^{3}$ Public Health Sciences, Fred Hutchinson Cancer Research Center, Seattle, WA 98109, USA \\ ${ }^{4}$ Department of Health Services, School of Public Health, University of Washington, Seattle, WA 98195, USA \\ ${ }^{5}$ Pharmaceutical Outcomes Research and Policy Program, School of Pharmacy, University of Washington, Seattle, WA 98195, USA \\ ${ }^{6}$ Health Services Research and Development, Department of Veterans Affairs, Puget Sound Health Care System, Seattle, \\ WA 98174, USA
}

Correspondence should be addressed to Elizabeth Trice Loggers; eloggers@seattlecca.org

Received 1 December 2015; Accepted 18 May 2016

Academic Editor: Vladimir F. Semiglazov

Copyright (C) 2016 Elizabeth Trice Loggers et al. This is an open access article distributed under the Creative Commons Attribution License, which permits unrestricted use, distribution, and reproduction in any medium, provided the original work is properly cited.

\begin{abstract}
Objective. It is unknown whether advanced imaging (AI) is associated with higher quality breast cancer (BC) care. Materials and Methods. Claims and Surveillance Epidemiology and End Results data were linked for women diagnosed with incident stage I-III BC between 2002 and 2008 in western Washington State. We examined receipt of preoperative breast magnetic resonance imaging (MRI) or AI (defined as computed tomography [CT]/positron emission tomography [PET]/PET/CT) versus mammogram and/or ultrasound (M-US) alone and receipt of guideline concordant care (GCC) using multivariable logistic regression. Results. Of 5247 women, $67 \%$ received M-US, 23\% MRI, 8\% CT, and 3\% PET/PET-CT. In 2002, 5\% received MRI and 5\% AI compared to 45\% and $12 \%$, respectively, in 2008. 79\% received GCC, but GCC declined over time and was associated with younger age, urban residence, less comorbidity, shorter time from diagnosis to surgery, and earlier year of diagnosis. Breast MRI was associated with GCC for lumpectomy plus radiation therapy (RT) (OR 1.55, 95\% CI 1.08-2.26, and $p=0.02$ ) and AI was associated with GCC for adjuvant chemotherapy for estrogen-receptor positive (ER+) BC (OR 1.74, 95\% CI 1.17-2.59, and $p=0.01)$. Conclusion. GCC was associated with prior receipt of breast MRI and AI for lumpectomy plus RT and adjuvant chemotherapy for ER+ BC, respectively.
\end{abstract}

\section{Introduction}

In the last 10 years, use of advanced imaging (defined here as magnetic resonance imaging (MRI), computed tomography (CT), or positron emission tomography (PET)) has become the single fastest growing health care service, outstripping all other tests and procedures [1-6]. This trend may be particularly pronounced for cancer patients, who typically receive multiple scans during all phases of cancer care (diagnosis, treatment, surveillance, and end of life) [7-10]. For example, PET scanning rates rose faster than any other imaging modality among both Medicare beneficiaries and
HMO enrollees of all ages with cancer [7-9]. Despite this rapid rate of growth, the relationship between advanced imaging and health outcomes is relatively unknown.

Amongst the imaging modalities, receipt of breast magnetic resonance imaging (MRI) in diagnosis and perioperative planning for breast cancer has received significant attention [11-17]. While breast MRI identifies occult cancers in individuals not identified as cases by clinical breast exam, mammography, or ultrasound $[13,18]$, there is no evidence that identification of clinically or mammographically occult tumors improves recurrence or survival outcomes [17-19]. Furthermore, two recent prospective randomized controlled 
trials of preoperative breast MRI showed no reduction in reexcision rates and a trend toward longer time to definitive therapy [20,21]. Findings such as these have led some to call for greater evidence linking receipt of advanced imaging to improvements in health care quality or outcomes $[17,19]$.

As there is evidence supporting higher quality outcomes among individuals receiving guideline concordant care (GCC) [20-24], one approach to assessing the clinical impact of advanced imaging is to examine whether receipt of preoperative breast MRI (or other advanced imaging) is associated with receipt of guideline concordant care (GCC) for breast cancer. While this relationship would not necessarily be causal, learning more about the association between receipt of advanced imaging and GCC could be informative to patients, insurers, and policy makers who struggle with defining "appropriateness" with respect to imaging studies. Therefore this study was designed to investigate associations between receipt of advanced imaging and GCC for breast cancer, focusing on well-known and accepted guidelines including, for example, radiation following lumpectomy and adjuvant chemotherapy for estrogen-receptor-positive disease.

\section{Materials and Methods}

This study was approved by the Institutional Review Boards at the participating institutions.

2.1. Study Population. We linked health plan enrollment and utilization files from three commercial health plans (Regence Blue Shield, Premera Blue Cross, and Uniform Medical Plan), one mixed-model health delivery system (Group Health Cooperative) and two publically funded health care programs (Medicaid and Medicare) with the western Washington Surveillance Epidemiology and End Results registry [25]. The linkage identified all adult (age: 18 years or older) females diagnosed with an incident invasive breast carcinoma between 2002 and 2008 .

We then excluded women who (1) had been diagnosed at autopsy or death, (2) had any additional breast cancer diagnosed within one year of the index diagnosis or bilateral cancer, (3) had stage IV cancer [26], (4) had a nonepithelial histology, (5) had no health plan claim in the 4 months following diagnosis, (6) received no surgery for treatment, (7) were not enrolled (gaps in coverage of no more than 60 days) for at least 12 months before and after surgery (unless they died), with neoadjuvant chemotherapy or without an imaging claim in the 4 months before surgery, and/or (8) were not eligible for at least one NCCN guideline and had no available information on race, comorbidity, or residence (Figures 1 and 2). Women enrolled in more than one health plan in the sixty days before and after diagnosis $(n=397)$ were also excluded from the analytic model to allow comparison among women enrolled in only one type of health plan.

We required women to have received their first breast surgery (either mastectomy or lumpectomy) within 4 months of the SEER date of diagnosis, since women who do not receive definitive surgery are substantially different. To be guideline concordant, care had to occur within one year of surgery; however, some women receive mastectomy or further surgery for positive margins following an initial lumpectomy. To address this, we looked up to four months after a lumpectomy for evidence of a mastectomy or further surgery and used the date of the final surgery (also referred to as the "last" surgery date) as the beginning of the period in which to determine whether guideline concordant care had been received (Figure 2 ). Women receiving a mastectomy after an initial lumpectomy were classified as receiving a mastectomy (along with all other women who received an initial mastectomy without a preceding lumpectomy).

2.2. Identification and Classification of Imaging. We focused on imaging used for staging and treatment planning before definitive surgery for breast cancer; thus, imaging was anchored to surgery date rather than diagnosis date (Figure 2). We included all imaging occurring for four months prior to the first surgery through the last surgery (when additional surgery occurred). We used the presence of at least one Current Procedural Terminology (CPT) code to identify mammograms with or without ultrasound, MRI, CT, and PET/PET-CT. Women were classified into mutually exclusive and hierarchical categories as receiving (1) no imaging besides mammography or ultrasound, (2) breast MRI, and (3) other advanced imaging (CT and/or PET/PET-CT). Finally, we present CT separate from PET/PET-CT in Table 1 to demonstrate differences in use; however for the multivariable analysis in which guideline concordant care is the outcome, we included CT with PET/PET-CT as described above.

2.3. Defining Treatment and Guideline Concordant Care. We used CPT codes to identify surgery (mastectomy and lumpectomy) and radiation $\mathrm{CPT}$ and/or Healthcare Common Procedural Coding System (HCPCS) J-code to identify chemotherapy receipt within one year of the last surgery. Tumor characteristics (i.e., size and receptor status) and lymph node status were determined via SEER data.

Definitions of GCC were derived from National Comprehensive Cancer Network (NCCN) published guidelines [27]. To increase the likelihood that there was wide clinical support (i.e., awareness of and agreement on the importance of the guidelines in the clinical care of early stage breast cancer) for the inclusion of our study guidelines throughout the study period, we selected guidelines based on two criteria: (1) data supporting selection of the guideline had existed for at least 5 years before the start of the study period (2002) and (2) each guideline was present in the NCCN guidelines for the entire study period. Using these criteria, four guidelines were operationalized for this study ( $N$ received $/ N$ eligible for measure): (1) adjuvant radiation receipt following lumpectomy (Radiation following Lumpectomy) (3,736/4085, 91.5\%), (2) radiation receipt following mastectomy if 4 or more axillary lymph nodes were positive (stage III disease) (Radiation following Mastectomy for Stage III) (285/321, 88.8\%), (3) adjuvant chemotherapy received for women with estrogenreceptor positive tumors with at least one positive lymph node (Chemotherapy for ER+Disease) $(929 / 1,453,63.9 \%)$, and (4) adjuvant chemotherapy received for women with ERtumors, $>1$ centimeter or with at least one positive lymph 


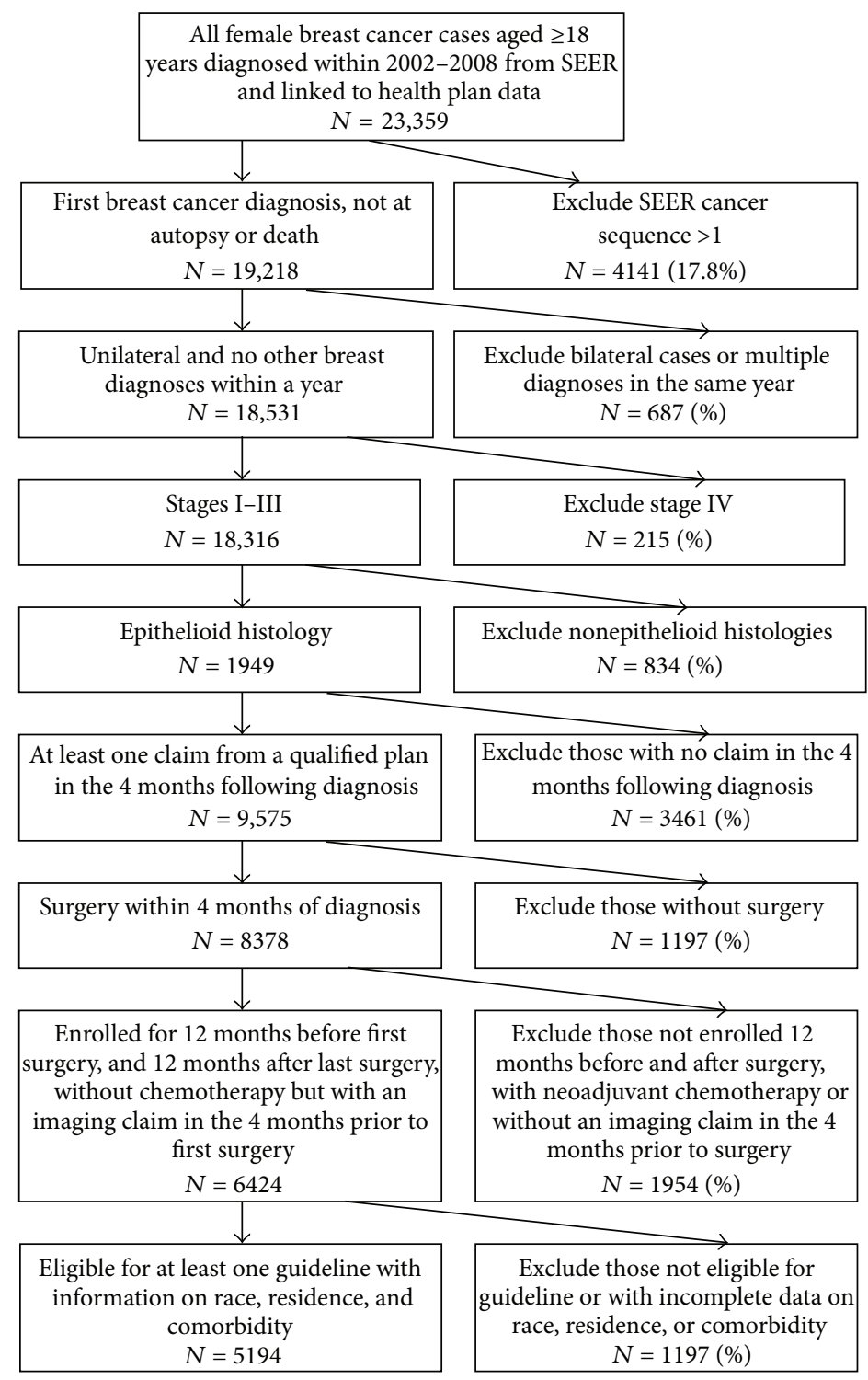

FIgURE 1: Study CONSORT diagram.

SEER date of

diagnosis

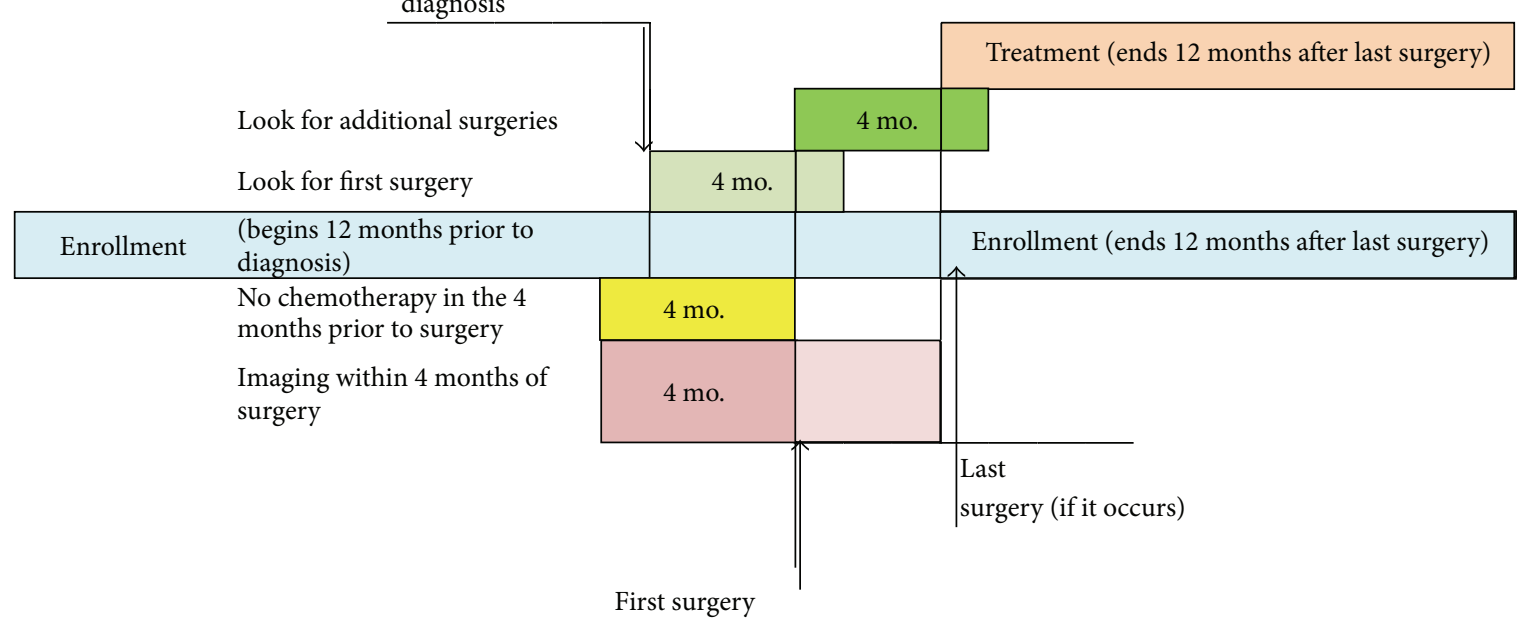

FIGURE 2: Study schema for identifying event windows. 
TABLE 1: Characteristics of 5,247 women receiving different types of imaging (in mutually exclusive categories ${ }^{1}$ ) prior to definitive surgery for early stage breast cancer.

\begin{tabular}{|c|c|c|c|c|c|}
\hline & $\begin{array}{c}\text { Mammogram/ultrasound }{ }^{1} \\
(n=3,525,67.2 \%)\end{array}$ & $\begin{array}{c}\text { Breast MRI }{ }^{2} \\
(n=1,190,22.7 \%)\end{array}$ & $\begin{array}{c}\mathrm{CT}^{3} \\
(n=394,7.5 \%) \\
\end{array}$ & $\begin{array}{l}\text { PET/PET-CT } \\
(n=138,2.6 \%)\end{array}$ & $\begin{array}{l}\text { Total }(\%) \\
(n=5,247) \\
\end{array}$ \\
\hline $\begin{array}{l}\text { Age at diagnosis (mean } \pm \text { standard } \\
\text { deviation) }\end{array}$ & $68.2 \pm 12.2$ & $61.1 \pm 12.0$ & $64.4 \pm 13.2$ & $59.8 \pm 13.2$ & $66.1 \pm 12.7$ \\
\hline \multicolumn{6}{|l|}{ Age at diagnosis } \\
\hline$\leq 50$ years ${ }^{*}$ & $290(8.2 \%)$ & $218(18.3 \%)$ & $62(15.7 \%)$ & $38(13.8 \%)$ & $599(11.4 \%)$ \\
\hline $51-64$ years & $946(26.8 \%)$ & $484(40.7 \%)$ & $113(28.7 \%)$ & $62(44.9 \%)$ & $1,605(30.6 \%)$ \\
\hline $65-70$ years & $677(19.2 \%)$ & $191(16.1 \%)$ & $83(21.1 \%)$ & $20(14.5 \%)$ & $971(18.5 \%)$ \\
\hline$\geq 71$ years $^{*}$ & $1,612(47.1 \%)$ & $297(24.9 \%)$ & $136(26.5 \%)$ & $18(19.5 \%)$ & $2,072(39.5 \%)$ \\
\hline \multicolumn{6}{|l|}{ Race } \\
\hline White & $3,267(92.7 \%)$ & $1,107(93.0 \%)$ & $359(91.1 \%)$ & $122(88.4 \%)$ & $4,855(92.5 \%)$ \\
\hline Non-White* & $258(7.3 \%)$ & $83(7.0 \%)$ & $35(8.9 \%)$ & $16(11.6 \%)$ & $392(7.5 \%)$ \\
\hline \multicolumn{6}{|l|}{ Race/ethnicity } \\
\hline White non-Hispanic & $3,232(91.7 \%)$ & $1,098(92.3 \%)$ & $353(89.6 \%)$ & $121(87.7 \%)$ & $4,804(91.6 \%)$ \\
\hline Non-White and/or Hispanic ${ }^{*}$ & $293(8.3 \%)$ & $92(7.7 \%)$ & $41(10.4 \%)$ & $17(12.3 \%)$ & $443(8.4 \%)$ \\
\hline \multicolumn{6}{|l|}{ Rural/urban residence } \\
\hline Urban & $3,101(88.0 \%)$ & $1,099(92.4 \%)$ & $345(87.6 \%)$ & $127(92.0 \%)$ & $4,672(89.0 \%)$ \\
\hline Rural & $424(12.0 \%)$ & $91(7.6 \%)$ & $49(12.4 \%)$ & $11(8.0 \%)$ & $575(11.0 \%)$ \\
\hline \multicolumn{6}{|l|}{ Health insurer type } \\
\hline Medicare & $1,898(53.8 \%)$ & $473(39.7 \%)$ & $210(53.3 \%)$ & $50(36.2 \%)$ & $2,631(50.1 \%)$ \\
\hline Fee for service/managed care ${ }^{*}$ & $1612(45.7 \%)$ & $717(60.3 \%)$ & $169(42.9 \%)$ & $71(51.4 \%)$ & $2401(45.8 \%)$ \\
\hline Medicaid $^{6}$ & $116(3.3 \%)$ & $44(3.7 \%)$ & $35(8.9 \%)$ & $20(14.5 \%)$ & $215(4.1 \%)$ \\
\hline \multicolumn{6}{|l|}{2000 Census tract median income } \\
\hline $\begin{array}{l}\text { Median income ( } \pm \text { standard } \\
\text { deviation) }\end{array}$ & $48,819 \pm 15,626$ & $53,972 \pm 16,619$ & $50,570 \pm 19,283$ & $49,451 \pm 18,460$ & $50,250 \pm 16,338$ \\
\hline$<\$ 41,100$ & $944(26.8 \%)$ & $219(18.4 \%)$ & $105(26.6 \%)$ & $37(26.8 \%)$ & $1,305(24.9 \%)$ \\
\hline$\$ 41,101-50,400$ & $979(27.8 \%)$ & $261(21.9 \%)$ & $87(22.1 \%)$ & $36(26.1 \%)$ & $1,363(26.0 \%)$ \\
\hline$\$ 50,401-61,700$ & $845(24.0 \%)$ & $340(28.6 \%)$ & $97(24.6 \%)$ & $28(20.2 \%)$ & $1,310(25.0 \%)$ \\
\hline$\$ 61,701+$ & $757(21.5 \%)$ & $370(31.1 \%)$ & $105(26.6 \%)$ & $37(26.8 \%)$ & $1,269(24.2 \%)$ \\
\hline \multicolumn{6}{|l|}{ Year of diagnosis } \\
\hline $2002-2005^{*}$ & $2204(62.5 \%)$ & $366(30.7 \%)$ & $201(51.1 \%)$ & $19(13.8 \%)$ & $2790(53.2 \%)$ \\
\hline 2006 & $541(15.3 \%)$ & $206(17.3 \%)$ & $62(15.7 \%)$ & $27(19.6 \%)$ & $836(15.9 \%)$ \\
\hline 2007 & $447(12.7 \%)$ & $262(22.0 \%)$ & $75(19.0 \%)$ & $50(36.2 \%)$ & $834(15.9 \%)$ \\
\hline 2008 & $333(9.5 \%)$ & $356(30.0 \%)$ & $56(14.2 \%)$ & $42(30.4 \%)$ & $787(15.0 \%)$ \\
\hline \multicolumn{6}{|l|}{ Comorbidity (CITE) } \\
\hline 0 & $2,668(75.7 \%)$ & $1,032(86.7 \%)$ & $309(78.4 \%)$ & $106(76.8 \%)$ & $4,115(78.4 \%)$ \\
\hline$\geq 1^{*}$ & $857(24.3 \%)$ & $158(13.2 \%)$ & $85(21.6 \%)$ & $32(23.2 \%)$ & $1132(21.6 \%)$ \\
\hline \multicolumn{6}{|l|}{$\begin{array}{l}\text { Time from diagnosis to definitive } \\
\text { surgery }\end{array}$} \\
\hline Mean days \pm standard deviation & $26.1 \pm 17.5$ & $31.8 \pm 18.7$ & $32.1 \pm 20.0$ & $38.4 \pm 24.5$ & $28.1 \pm 18.5$ \\
\hline \multicolumn{6}{|l|}{$\begin{array}{l}\text { Time from diagnosis to definitive } \\
\text { surgery }\end{array}$} \\
\hline $0-14$ days $^{*}$ & $936(26.5 \%)$ & $161(13.5 \%)$ & $62(15.7 \%)$ & $16(11.6 \%)$ & $1175(22.4 \%)$ \\
\hline 15-30 days & $1,394(39.5 \%)$ & $495(41.6 \%)$ & $147(37.3 \%)$ & $48(34.8 \%)$ & $2,084(39.7 \%)$ \\
\hline
\end{tabular}


TABLE 1: Continued.

\begin{tabular}{|c|c|c|c|c|c|}
\hline & $\begin{array}{c}\text { Mammogram/ultrasound }{ }^{1} \\
(n=3,525,67.2 \%)\end{array}$ & $\begin{array}{c}\text { Breast MRI }{ }^{2} \\
(n=1,190,22.7 \%)\end{array}$ & $\begin{array}{c}\mathrm{CT}^{3} \\
(n=394,7.5 \%) \\
\end{array}$ & $\begin{array}{l}\text { PET/PET-CT } \\
(n=138,2.6 \%)\end{array}$ & $\begin{array}{l}\text { Total }(\%) \\
(n=5,247) \\
\end{array}$ \\
\hline $31-60$ days & $1,043(29.6 \%)$ & $444(37.3 \%)$ & $155(39.3 \%)$ & $52(37.7 \%)$ & $1,694(32.3 \%)$ \\
\hline 61 or more days & $152(4.3 \%)$ & $90(7.6 \%)$ & $30(7.6 \%)$ & $22(5.9 \%)$ & $294(0.1 \%)$ \\
\hline
\end{tabular}

${ }^{*}$ Due to small cells, some rows have been suppressed by aggregating across other rows.

${ }^{1}$ Women may receive more than one type of imaging but are categorized only once in the table by the highest intensity of imaging. The hierarchy is PET/PETCT $>$ CT $>$ MRI > mammogram with or without ultrasound (as the base category).

${ }^{2} \mathrm{MRI}$ : magnetic resonance imaging.

${ }^{3} \mathrm{CT}$ : computed tomography.

${ }^{4}$ PET/PET-CT: positron emission tomography.

${ }^{5}$ Patients may be included in more than one health insurance category if dual-enrolled. This categorization allows nonqualifying enrollment in the period \pm 60 days of diagnosis.

${ }^{6}$ The possibility of being insufficient claims or Medicaid with limited enrollment prior to diagnosis.

node (Chemotherapy for ER- Disease) (578/816, 70.8\%). We did not examine guidelines associated with adjuvant endocrine therapy receipt because of the inability to access these data through claims.

In order to assess guideline concordance, we first assessed whether each woman was eligible for the respective guideline. For example, surgical categories were mutually exclusive, so women who were eligible for the Radiation following Lumpectomy guideline were not eligible for the Mastectomy following Radiation guideline; similarly women eligible for the Chemotherapy for ER+Disease guideline were not eligible for the Chemotherapy for ER-Disease guideline. We defined concordance for women for each eligible guideline.

2.4. Covariates. We considered sociodemographic variables, comorbidity, health plan characteristics, diagnosis year, and time from diagnosis to definitive surgery as potential confounding variables. Using SEER, we examined diagnosis year, age, race/ethnicity, urban or rural residence (based on her zip code diagnosis using the 2000 US Census [28]), and median household income (US Census tract at diagnosis). Comorbidity was assessed using claims data from health plans from one year to 30 days before the first surgical procedure [29]. An exception was made for determining comorbidity in Medicaid patients due to differences in enrollment patterns; we looked from four months to one year prior to the first surgery depending upon available enrollment data. Payer characteristics included health plan type (e.g., fee for service, managed care, Medicaid, and Medicare). Time from diagnosis to definitive surgery was calculated using the SEER date of diagnosis and the claims date of last surgery. Stage and/or tumor characteristics and estrogen receptor status are not included in the model as possible confounding variables because they were used in the definition of the GCC as described above.

2.5. Statistical Analysis. We performed univariate logistic regressions to identify factors associated with each imaging category. We used results of these analyses to construct multivariable logistic regression models comparing the breast MRI and other advanced imaging receipt to mammogram \pm ultrasound. Because of the small number of women eligible for receipt of some guidelines and the relatively large number of independent variables selected a priori, some variable categories were collapsed (i.e., race and time to definitive surgery) or entered into the model as continuous variables (i.e., age, comorbidity, and income).

\section{Results}

The final sample included 5,247 subjects, of whom $67 \%$ received only mammogram and/or ultrasound, $23 \%$ received breast MRI, $8 \%$ received CT, and 3\% received PET/PET-CT before definitive surgery (see Table 1). In 2002, 89\% of women received a mammogram and/or US, while $5 \%$ of women received an MRI and 5\% received advanced imaging; by 2008 the percentages changed to $42 \%, 45 \%$, and $12 \%$, respectively. Younger women were more likely to have received breast MRI and PET/PET-CT. Women residing in urban locations and who had higher incomes and fewer comorbidities were more likely to have received breast MRI, as were women diagnosed in later years of the study.

Most women (79\%) received all GCC for which they were eligible (Table 2); guideline concordance for women receiving chemotherapy was lower than for other guidelines (64\% $\mathrm{ER}+$ and $71 \% \mathrm{ER}-$ ). In the model examining associations between overall GCC and receipt of advanced imaging, older age, living in a nonurban setting, increasing comorbidity, increasing time from diagnosis to surgery, and later year of cancer diagnosis were negatively associated with receipt of all GCC for which a woman was eligible (Table 3). The likelihood of receiving GCC appeared to decline over time (OR 0.74, $95 \%$ CI $0.55-0.99$, and $p=0.04$ in 2004; OR $0.66,95 \%$ CI $0.50-0.89$, and $p=0.01$ in 2008).

MRI receipt was associated with increased odds of receiving radiation following a lumpectomy (OR 1.55; 95\% CI 1.08-2.26; $p=0.02$ ), but not with advanced imagining (Table 4). However, advanced imaging receipt was associated with increased odds that a woman would receive adjuvant chemotherapy for ER-positive disease (OR 1.74; 95\% CI 1.17$2.59 ; p=0.01)$. No other statistically significant associations were found between MRI or advanced imaging receipt and GCC.

\section{Discussion}

Our study is among the first to investigate the relationship between advanced imaging and receipt of guideline 
TABLE 2: Distribution of covariates by receipt of all guideline concordant care for which a woman was eligible and by individual guideline, for women with early stage breast cancer.

\begin{tabular}{|c|c|c|c|c|c|}
\hline Variable & $\begin{array}{l}\text { All guideline } \\
\text { concordant care }\end{array}$ & $\begin{array}{c}\text { Radiation } \\
\text { following } \\
\text { Lumpectomy }\end{array}$ & $\begin{array}{c}\text { Radiation } \\
\text { following } \\
\text { Mastectomy }\end{array}$ & $\begin{array}{c}\text { Chemotherapy for } \\
\text { ER-positive } \\
\text { Disease }^{1} \\
\end{array}$ & $\begin{array}{l}\text { Chemotherapy for } \\
\text { ER-negative } \\
\text { Disease }^{2}\end{array}$ \\
\hline$N$ & 5,247 & 4,085 & 321 & 1,453 & 816 \\
\hline \multicolumn{6}{|l|}{ Concordant } \\
\hline Yes & $4,168(79.4 \%)$ & $3,736(91.5 \%)$ & $285(88.8 \%)$ & $929(63.9 \%)$ & $578(70.8 \%)$ \\
\hline No & $1,079(20.6 \%)$ & $349(8.5 \%)$ & $36(11.2 \%)$ & $524(36.1 \%)$ & $238(29.2 \%)$ \\
\hline \multicolumn{6}{|l|}{ Imaging } \\
\hline Mammogram/US & $3,525(67.2 \%)$ & $2,888(70.7 \%)$ & $148(46.1 \%)$ & $858(59.1 \%)$ & $542(66.4 \%)$ \\
\hline Breast MRI & $1,190(22.7 \%)$ & $921(22.5 \%)$ & $82(25.5 \%)$ & $350(24.1 \%)$ & $145(17.8 \%)$ \\
\hline $\mathrm{PET} / \mathrm{CT}$ & $532(10.1 \%)$ & $276(6.8 \%)$ & $91(28.3 \%)$ & $245(16.9 \%)$ & $129(15.8 \%)$ \\
\hline $\begin{array}{l}\text { Age }^{3} \text { (mean years } \pm \\
\text { standard deviation, } \\
\text { range) }\end{array}$ & $\begin{array}{c}66.1 \pm 12.7 \\
(26-103)\end{array}$ & $\begin{array}{c}66.4 \pm 12.2 \\
(26-103)\end{array}$ & $\begin{array}{c}64.5 \pm 13.9 \\
(32-92)\end{array}$ & $\begin{array}{c}64.3 \pm 13.0 \\
(30-93)\end{array}$ & $64.2 \pm 13.8(26-96)$ \\
\hline \multicolumn{6}{|l|}{$\begin{array}{l}\text { Race (White } \\
\text { non-Hispanic) }\end{array}$} \\
\hline Yes & $4,804(91.6 \%)$ & $3,773(92.4 \%)$ & $284(88.5 \%)$ & $1,328(91.4 \%)$ & $718(88.0 \%)$ \\
\hline No & $443(8.4 \%)$ & $312(7.6 \%)$ & $37(11.5 \%)$ & $125(8.6 \%)$ & $98(12 \%)$ \\
\hline \multicolumn{6}{|l|}{ Rural/urban residence } \\
\hline Urban & $4,672(89.0 \%)$ & $3,632(88.9 \%)$ & $291(90.7 \%)$ & $1,295(89.1 \%)$ & $714(87.5 \%)$ \\
\hline Large & $360(6.9 \%)$ & $283(6.9 \%)$ & $18(5.6 \%)$ & $104(7.2 \%)$ & $61(7.5 \%)$ \\
\hline Small & $215(4.1 \%)$ & $170(2.4 \%)$ & $12(3.7 \%)$ & $54(3.7 \%)$ & $41(5.0 \%)$ \\
\hline \multicolumn{6}{|l|}{ Health insurer type } \\
\hline Medicare & $2,498(47.6 \%)$ & $1,981(48.5 \%)$ & $133(41.4 \%)$ & $661(45.5 \%)$ & $339(41.5 \%)$ \\
\hline Fee for service & $1,059(20.2 \%)$ & $822(20.1 \%)$ & $61(19.0 \%)$ & $307(21.0 \%)$ & $177(21.7 \%)$ \\
\hline Managed care & $1,334(25.4 \%)$ & $1,027(25.1 \%)$ & $97(30.2 \%)$ & $370(25.5 \%)$ & $233(28.6 \%)$ \\
\hline Medicaid & $189(3.6 \%)$ & $125(3.1 \%)$ & $18(5.6 \%)$ & $72(5.0 \%)$ & $42(5.1 \%)$ \\
\hline Multiple & $167(3.2 \%)$ & $130(3.2 \%)$ & $12(3.7 \%)$ & $43(3.0 \%)$ & $25(3.1 \%)$ \\
\hline $\begin{array}{l}\text { Log of median income } \\
\text { (mean } \pm \text { standard } \\
\text { deviation, range) }\end{array}$ & $\begin{array}{l}10.8 \pm 0.3 \\
(9.3-11.8)\end{array}$ & $\begin{array}{l}10.8 \pm 0.3 \\
(9.3-11.8)\end{array}$ & $\begin{array}{l}10.8 \pm 0.3 \\
(9.6-11.8)\end{array}$ & $\begin{array}{l}10.8 \pm 0.3 \\
(9.3-11.8)\end{array}$ & $\begin{array}{l}10.8 \pm 0.3 \\
(9.3-11.8)\end{array}$ \\
\hline \multicolumn{6}{|l|}{ Year of diagnosis } \\
\hline 2002 & $622(11.9 \%)$ & $491(12.0 \%)$ & $40(12.5 \%)$ & $174(12.0 \%)$ & $87(10.7 \%)$ \\
\hline 2003 & $663(12.6 \%)$ & $502(12.3 \%)$ & $43(13.4 \%)$ & $177(12.2 \%)$ & $113(13.8 \%)$ \\
\hline 2004 & $673(12.8 \%)$ & $518(12.7 \%)$ & $46(14.3 \%)$ & $196(13.5 \%)$ & $114(14.0 \%)$ \\
\hline 2005 & $832(15.9 \%)$ & $642(15.7 \%)$ & $51(15.9 \%)$ & $235(16.2 \%)$ & $129(15.8 \%)$ \\
\hline 2006 & $836(15.9 \%)$ & $672(16.5 \%)$ & $45(14.0 \%)$ & $209(14.4 \%)$ & $128(15.7 \%)$ \\
\hline 2007 & $834(15.9 \%)$ & $641(15.7 \%)$ & $58(18.1 \%)$ & $248(17.1 \%)$ & $126(15.4 \%)$ \\
\hline 2008 & $787(15.0 \%)$ & $619(15.2 \%)$ & $38(11.8 \%)$ & $214(14.7 \%)$ & $119(14.6 \%)$ \\
\hline $\begin{array}{l}\text { Comorbidity }^{4} \text { (mean } \pm \\
\text { standard deviation, } \\
\text { range) }\end{array}$ & $\begin{array}{c}0.2 \pm 0.4 \\
(0-3.4)\end{array}$ & $\begin{array}{c}0.1 \pm 0.4 \\
(0-3.4)\end{array}$ & $\begin{array}{c}0.2 \pm 0.4 \\
(0-2.5)\end{array}$ & $\begin{array}{c}0.2 \pm 0.4 \\
(0-3.3)\end{array}$ & $\begin{array}{c}0.2 \pm 0.4 \\
(0-3.1)\end{array}$ \\
\hline \multicolumn{6}{|l|}{$\begin{array}{l}\text { Time from diagnosis to } \\
\text { definitive surgery } \\
\text { (days) }\end{array}$} \\
\hline$\leq 60$ & $4,683(89.3 \%)$ & $3,665(89.7 \%)$ & $286(89.1 \%)$ & $1,280(88.1 \%)$ & $740(90.7 \%)$ \\
\hline$>60$ & $564(10.7 \%)$ & $420(10.3 \%)$ & $35(10.9 \%)$ & $173(11.9 \%)$ & $76(9.3 \%)$ \\
\hline
\end{tabular}


TABLE 3: Multivariable model results for receipt of all guideline concordant care for which a woman was eligible for 5194 women with early stage breast cancer, emphasizing the relationship between breast MRI and advanced imaging.

\begin{tabular}{|c|c|c|c|}
\hline & Odds ratio & $\begin{array}{c}95 \% \\
\text { confidence } \\
\text { intervals }\end{array}$ & $p$ value \\
\hline Mammogram/ultrasound & Ref. & - & - \\
\hline Breast MRI & 1.21 & $(0.98,1.51)$ & 0.07 \\
\hline CT, PET, and PET/CT & 0.87 & $(0.68,1.12)$ & 0.28 \\
\hline Age & 0.93 & $(0.91,0.93)$ & $<0.0001$ \\
\hline White, non-Hispanic & Ref. & - & - \\
\hline No & 0.96 & $(0.73,1.28)$ & 0.78 \\
\hline $\begin{array}{l}\text { Rural/urban residence } \\
\text { (urban) }\end{array}$ & Ref. & - & - \\
\hline Large rural & 0.65 & $(0.50,0.86)$ & 0.001 \\
\hline Small rural/isolated & 0.73 & $(0.52,1.04)$ & 0.08 \\
\hline Plan type (Medicare) & Ref. & - & - \\
\hline Fee for service & 1.07 & $(0.79,1.44)$ & 0.67 \\
\hline Managed care & 1.08 & $(0.89,1.32)$ & 0.43 \\
\hline Medicaid & 0.67 & $(0.41,1.13)$ & 0.12 \\
\hline Multiple & 0.99 & $(0.66,1.51)$ & 0.95 \\
\hline Log median income & 1.17 & $(0.91,1.51)$ & 0.22 \\
\hline Year of diagnosis & Ref. & - & - \\
\hline 2003 & 0.77 & $(0.58,1.03)$ & 0.07 \\
\hline 2004 & 0.74 & $(0.55,0.99)$ & 0.04 \\
\hline 2005 & 0.73 & $(0.55,0.96)$ & 0.03 \\
\hline 2006 & 0.73 & $(0.55,0.97)$ & 0.03 \\
\hline 2007 & 0.75 & $(0.56,0.99)$ & 0.05 \\
\hline 2008 & 0.66 & $(0.50,0.89)$ & 0.01 \\
\hline Comorbidity ${ }^{1}$ & 0.65 & $(0.55,0.77)$ & $<0.0001$ \\
\hline \multicolumn{4}{|l|}{$\begin{array}{l}\text { Diagnosis to definitive } \\
\text { surgery }\end{array}$} \\
\hline$\leq 60$ days & Ref. & - & - \\
\hline$>60$ days & 0.65 & $(0.52,0.81)$ & 0.0001 \\
\hline
\end{tabular}

MRI: magnetic resonance imaging.

CT: computed tomography.

PET: positron emission tomography.

${ }^{1}$ Klabunde comorbidity index.

concordant care. We found a rapid rate of increase in breast MRI and advanced imaging and a relatively high percentage of women who received all guideline concordant care. MRI was associated with an increased likelihood of receiving radiation following lumpectomy and advanced imaging was associated with an increased likelihood of receiving chemotherapy for ER-positive disease.

In light of our results, advanced imaging may be associated with temporal trends in (increasing) aggressiveness of care or unmeasured clinical or patient-related factors that are also associated with guideline concordant care. For example, clinicians may both scan and treat more aggressively patients they view as having higher risk disease. Patient preference and access may also play a role in both receipt of advanced
TABLE 4: Multivariable results by guideline for the association between receipt of advanced imaging and receipt of guideline concordant care for women with early stage breast cancer controlling for confounding variables.

\begin{tabular}{lccc}
\hline Guideline & Odds ratio & $\begin{array}{c}95 \% \\
\text { confidence } \\
\text { interval }\end{array}$ & $p$ value \\
\hline $\begin{array}{l}\text { Radiation following } \\
\text { Lumpectomy }(N=4,085)\end{array}$ & & & \\
$\quad$ Mammogram/ultrasound & Ref. & - & - \\
$\quad$ Breast MRI & 1.55 & $(1.08,2.26)$ & 0.02 \\
$\quad$ CT, PET, and PET/CT & 1.02 & $(0.67,1.63)$ & 0.92 \\
\hline $\begin{array}{l}\text { Radiation following } \\
\text { Mastectomy }(N=321)\end{array}$ & & & \\
$\quad \begin{array}{l}\text { Mammogram/ultrasound } \\
\text { Breast MRI }\end{array}$ & Ref. & - & - \\
$\quad$ CT, PET, and PET/CT & 0.53 & $(0.19,1.53)$ & 0.24 \\
\hline
\end{tabular}

Chemotherapy for ER+ Disease

$(N=1,453)$

$\begin{array}{lccc}\text { Mammogram/ultrasound } & \text { Ref. } & - & - \\ \text { Breast MRI } & 1.37 & (0.96,1.96) & 0.09 \\ \text { CT, PET, and PET/CT } & 1.74 & (1.17,2.59) & 0.01\end{array}$

Chemotherapy for ER- Disease

$(N=816)$

Mammogram/ultrasound

Breast MRI

$\begin{array}{ll}\text { Ref. } & - \\ 1.07 & (0.58,\end{array}$

2.00)

0.83

CT, PET, and PET/CT

1.61

$(0.89,2.97)$

0.12

$\mathrm{ER}+:$ estrogen receptor positive.

ER-: estrogen receptor negative.

MRI: magnetic resonance imaging.

CT: computed tomography.

PET: positron emission tomography.

Confounding variables included age, race, residence, plan type, income, year, comorbidity, and time from diagnosis to definitive surgery.

imaging and guideline concordant care, both of which we were unable to account for in this study. Factors associated with a greater likelihood of achieving all guideline concordant care included younger age, urban residence, less comorbid disease, and shorter time from diagnosis to definitive surgery, consistent with prior studies [30-33]. Some of these factors have been previously associated with advanced imaging by our team [25]. Finally, the lack of significance for breast MRI and advanced imaging in relation to some study guidelines may be due to a lack of power $(N=321$ eligible women for the Radiation following Mastectomy guideline and $N=$ 816 eligible women for the Chemotherapy for ER-Disease guideline).

Of interest in this study is the observation that the proportion of women receiving guideline concordant care may be declining over time. We are unaware of any other studies that have reported similar results. This finding may be incidental or there may have been other guidelines or clinical practices that were not included in this study that affected care during the study period. Also, while we did not evaluate 
this hypothesis, the reduction in guideline concordant care might be due to increasing rates of lymph node dissection and receptor-status testing over the study period, which may lead to more women being eligible for more guidelines and, in turn, more opportunities to fail to receive "all" guideline concordant care. Alternatively, reductions in the rate of receipt of all guideline concordant care may be due to greater awareness on the part of clinicians and/or patients of the longterm negative consequences of adjuvant radiation [34-36] and chemotherapy [37-40] and in some cases the potentially limited benefit of adjuvant chemotherapy [33, 41-43], leading to lower rates of use despite guideline recommendations.

While this study is the first to examine associations between advanced imaging and guidelines concordant care in a large, population-based setting, it does have limitations. This study cannot address why a woman did not receive guideline concordant care. It is possible that some women did not receive guideline recommended care appropriately due to complications from earlier treatment, comorbidities, personal preference, or other reasons. We were unable to include all guidelines, such as adjuvant endocrine therapy receipt, given limitations in claims data. Indication for the exam was unavailable; it is possible that women received imaging for reasons other than their cancer diagnosis. In addition, our study includes women over the age of 70 , for whom the value of adjuvant chemotherapy is less clear.

In conclusion, this study characterizes the relationship between MRI and advanced imaging receipt and overall quality of care for women with early stage breast cancer, both topics of increasing importance as the goal of achieving highquality care at the lowest cost is pursued. Future research should investigate the clinical rationale and patient factors influencing MRI and advanced imaging receipt to better inform the relationship between advanced imaging and receipt of high-quality, guideline concordant breast cancer care.

\section{Ethical Approval}

This study was approved by the Institutional Review Boards at the participating institutions.

\section{Disclosure}

Steven Zeliadt is presently an Investigator at the Department of Veterans Affairs, Puget Sound Health Care System, Health Services Research and Development, Seattle, WA. Study sponsors had no role in the study design, collection, analysis, and interpretation of data, the writing of the paper, or the decision to submit the paper for publication. The content is solely the responsibility of the authors and does not necessarily represent the official views of the participating health plans, the National Cancer Institute, the National Institutes of Health, or the Department of Veterans Affairs.

\section{Competing Interests}

The authors declare no competing interests.

\section{Acknowledgments}

The authors thank the ADVICE research staff for invaluable assistance with data preparation and research administration: Lydia Andris, Susan Brandzel, Alexis Drum, Holly James, Greg Klein, Catherine Fedorenko, Karma L. Kreizenbeck, David Mummy, and Arvind Ramaprasan. This study was supported by the National Cancer Institute Grant no. CA148433. Assistance on coding used for this study was provided by collaborators from another grant from the National Cancer Institute: no. CA148577 (imaging) and no. CA148185 (infusion). The collection of cancer incidence data used in this study was supported by the Cancer Surveillance System of the Fred Hutchinson Cancer Research Center, which is funded by Contract nos. N01-CN-67009 and N01-PC-35142 from the SEER Program of the National Cancer Institute with additional support from the Fred Hutchinson Cancer Research Center and the State of Washington. The research reported here was supported by Department of Veterans Affairs, Veterans Health Administration, Health Services Research and Development Service grant.

\section{References}

[1] United States Golf Association (USGA), Medicare: Trends in Fees, Utilization, and Expenditures for Imaging Services before and after Implementation of the Deficit Reduction Act of 2005, United States Golf Association (USGA), Washington, DC, USA, 2008.

[2] Office USGA, Medicare Part B Imaging Services: Rapid Spending Growth and Shift to Physician Offices Indicate Need for CMS to Consider Additional Management Practices, Office USGA, Washington, DC, USA, 2008.

[3] Office USGA, Medicare: Referrals to Physician-Owned Imaging Facilities Warrant HCFA's Scrutiny, USGA, Washington, DC, USA, 1994.

[4] GAO, Higher Use of Advanced Imaging Services by Proviers Who Self-Refer Costing Medicare Millions, GAO, Washington, DC, USA, 2012.

[5] M. Bhargavan and J. H. Sunshine, "Utilization of radiology services in the United States: levels and trends in modalities, regions, and populations," Radiology, vol. 234, no. 3, pp. 824832, 2005.

[6] R. Smith-Bindman, D. L. Miglioretti, and E. B. Larson, "Rising use of diagnostic medical imaging in a large integrated health system," Health Affairs, vol. 27, no. 6, pp. 1491-1502, 2008.

[7] M. A. Dinan, L. H. Curtis, B. G. Hammill et al., "Changes in the use and costs of diagnostic imaging among medicare beneficiaries with cancer, 1999-2006," JAMA-Journal of the American Medical Association, vol. 303, no. 16, pp. 1625-1631, 2010.

[8] M. A. Dinan, L. H. Curtis, W. R. Carpenter et al., "Variations in use of PET among medicare beneficiaries with non-small cell lung cancer, 1998-2007," Radiology, vol. 267, no. 3, pp. 807-817, 2013.

[9] E. T. Loggers, P. A. Fishman, M. C. Hornbrook et al., "Advanced imaging for managed care Medicare beneficiaries with cancer, 2001-2006," Journal of Oncology Practice, vol. 10, no. 4, pp. 231238, 2014. 
[10] Y.-Y. Hu, A. C. Kwok, W. Jiang et al., "High-cost imaging in elderly patients with stage IV cancer," Journal of the National Cancer Institute, vol. 104, no. 15, pp. 1164-1172, 2012.

[11] K. Pettit, M. E. Swatske, F. Gao et al., "The impact of breast MRI on surgical decision-making: are patients at risk for mastectomy?" Journal of Surgical Oncology, vol. 100, no. 7, pp. 553-558, 2009.

[12] W. A. Berg, L. Gutierrez, M. S. NessAiver et al., "Diagnostic accuracy of mammography, clinical examination, US, and MR imaging in preoperative assessment of breast cancer," Radiology, vol. 233, no. 3, pp. 830-849, 2004.

[13] R. J. Bleicher, R. M. Ciocca, B. L. Egleston et al., "Association of routine pretreatment magnetic resonance imaging with time to surgery, mastectomy rate, and margin status," Journal of the American College of Surgeons, vol. 209, no. 2, pp. 180-187, 2009.

[14] C. D. Lehman, W. DeMartini, B. O. Anderson, and S. B. Edge, "Indications for breast MRI in the patient with newly diagnosed breast cancer," Journal of the National Comprehensive Cancer Network, vol. 7, no. 2, pp. 193-200, 2009.

[15] M. Hulvat, N. Sandalow, A. Rademaker, I. Helenowski, and N. M. Hansen, "Time from diagnosis to definitive operative treatment of operable breast cancer in the era of multimodal imaging," Surgery, vol. 148, no. 4, pp. 746-751, 2010.

[16] V. M. Rao and D. C. Levin, "The overuse of diagnostic imaging and the choosing wisely initiative," Annals of Internal Medicine, vol. 157, no. 8, pp. 574-576, 2012.

[17] N. Houssami and D. F. Hayes, "Review of preoperative magnetic resonance imaging (MRI) in breast cancer: should MRI be performed on all women with newly diagnosed, early stage breast cancer?" CA Cancer Journal for Clinicians, vol. 59, no. 5, pp. 290-302, 2009.

[18] L. J. Solin, S. G. Orel, W.-T. Hwang, E. E. Harris, and M. D. Schnall, "Relationship of breast magnetic resonance imaging to outcome after breast-conservation treatment with radiation for women with early-stage invasive breast carcinoma or ductal carcinoma in situ," Journal of Clinical Oncology, vol. 26, no. 3, pp. 386-391, 2008.

[19] C. Kuhl, W. Kuhn, M. Braun, and H. Schild, "Pre-operative staging of breast cancer with breast MRI: one step forward, two steps back?" Breast, vol. 16, supplement 2, pp. 34-44, 2007.

[20] T. J. Smith and B. E. Hillner, "Ensuring quality cancer care by the use of clinical practice guidelines and critical pathways," Journal of Clinical Oncology, vol. 19, no. 11, pp. 2886-2897, 2001.

[21] B. C. Visser, Y. Ma, Y. Zak, G. A. Poultsides, J. A. Norton, and K. F. Rhoads, "Failure to comply with NCCN guidelines for the management of pancreatic cancer compromises outcomes," $H P B$, vol. 14, no. 8, pp. 539-547, 2012.

[22] N. Hébert-Croteau, J. Brisson, J. Latreille, M. Rivard, N. Abdelaziz, and G. Martin, "Compliance with consensus recommendations for systemic therapy is associated with improved survival of women with node-negative breast cancer," Journal of Clinical Oncology, vol. 22, no. 18, pp. 3685-3693, 2004.

[23] G. M. Boland, G. J. Chang, A. B. Haynes et al., "Association between adherence to National Comprehensive Cancer Network treatment guidelines and improved survival in patients with colon cancer," Cancer, vol. 119, no. 8, pp. 1593-1601, 2013.

[24] C. Bahtsevani, G. Udén, and A. Willman, "Outcomes of evidence-based clinical practice guidelines: a systematic review," International Journal of Technology Assessment in Health Care, vol. 20, no. 4, pp. 427-433, 2004.

[25] L. S. Gold, D. S. M. Buist, E. T. Loggers et al., "Advanced diagnostic breast cancer imaging: variation and patterns of care in Washington State," Journal of Oncology Practice, vol. 9, no. 5, pp. e194-e202, 2013.

[26] F. L. Greene, D. L. Page, I. D. Fleming et al., Eds., AJCC Cancer Staging Manual, Springer, New York, NY, USA, 6th edition, 2002.

[27] NCCN, Breast Cancer Screening and Diagnosis v.1.2010, National Comprehensive Cancer Network, 2010, http://www.nccn.org.

[28] US Census Bureau, State and County QuickFacts. Data Derived from Population Estimates, American Community Survey, Census of Population and Housing, State and County Housing Unit Estimates, County Business Patterns, Nonemployer Statistics, Economic Census, Survey of Business Owners, Building Permits, Consolidated Federal Funds Report, US Commerce Department, 2012, http://quickfacts.census.gov/qfd/states/53000.html.

[29] C. N. Klabunde, J. M. Legler, J. L. Warren, L.-M. Baldwin, and D. Schrag, "A refined comorbidity measurement algorithm for claims-based studies of breast, prostate, colorectal, and lung cancer patients," Annals of Epidemiology, vol. 17, no. 8, pp. 584590, 2007.

[30] N. Yao, S. A. Matthews, M. M. Hillemeier, and R. T. Anderson, "Radiation therapy resources and guideline-concordant radiotherapy for early-stage breast cancer patients in an underserved region," Health Services Research, vol. 48, no. 4, pp. 1433-1449, 2013.

[31] A. S. Hamilton, S. T. Fleming, D. Wang et al., "Clinical and demographic factors associated with receipt of non guidelineconcordant initial therapy for nonmetastatic prostate cancer," American Journal of Clinical Oncology, vol. 39, no. 1, pp. 55-63, 2016.

[32] L. L. Zullig, W. R. Carpenter, D. Provenzale, M. Weinberger, B. B. Reeve, and G. L. Jackson, "Examining potential colorectal cancer care disparities in the Veterans Affairs health care system," Journal of Clinical Oncology, vol. 31, no. 28, pp. 35793584, 2013.

[33] G. Kimmick, S. T. Fleming, S. A. Sabatino et al., "Comorbidity burden and guideline-concordant care for breast cancer," Journal of the American Geriatrics Society, vol. 62, no. 3, pp. 482-488, 2014.

[34] K. Holli, R. Saaristo, J. Isola, H. Joensuu, and M. Hakama, "Relative harms and merits of postoperative radiation following conservative surgery for low risk breast cancer," British Journal of Cancer, vol. 86, no. 2, pp. 310-311, 2002.

[35] K. H. Tjessem, S. Johansen, E. Malinen et al., "Long-term cardiac mortality after hypofractionated radiation therapy in breast cancer," International Journal of Radiation Oncology Biology Physics, vol. 87, no. 2, pp. 337-343, 2013.

[36] B. D. Smith, S. M. Bentzen, C. R. Correa et al., "Fractionation for whole breast irradiation: an American society for radiation oncology (ASTRO) evidence-based guideline," International Journal of Radiation Oncology Biology Physics, vol. 81, no. 1, pp. 59-68, 2011.

[37] L. M. Morton, G. M. Dores, M. A. Tucker et al., "Evolving risk of therapy-related acute myeloid leukemia following cancer chemotherapy among adults in the United States, 1975-2008," Blood, vol. 121, no. 15, pp. 2996-3004, 2013.

[38] J. E. Karp, A. Blackford, K. Visvanathan et al., "Myelodysplatic syndrome and/or acute myelogenous leukemia (MDS and/or AML) after a breast cancer diagnosis: the National Comprehensive Cancer Network (NCCN) experience," Cancer Research, vol. 72, supplement 24, abstract S3-5, pp. 2195-2196, 2014.

[39] L. Tarantini, S. Gori, P. Faggiano et al., "Adjuvant trastuzumab cardiotoxicity in patients over 60 years of age with early breast 
cancer: a multicenter cohort analysis," Annals of Oncology, vol. 23, no. 12, pp. 3058-3063, 2012.

[40] V. Adamo, G. R. R. Ricciardi, B. Adamo et al., "The risk of toxicities from trastuzumab, alone or in combination, in an elderly breast cancer population," Oncology, vol. 86, no. 1, pp. 16-21, 2014.

[41] V. Seror, P. Marino, F. Bertucci et al., "Breast cancer patients' views on the use of genomic testing to guide decisions about their postoperative chemotherapy," Public Health Genomics, vol. 16, no. 3, pp. 110-117, 2013.

[42] A. Ring, H. Harder, C. Langridge, R. S. Ballinger, and L. J. Fallowfield, "Adjuvant chemotherapy in elderly women with breast cancer (AChEW): an observational study identifying MDT perceptions and barriers to decision making," Annals of Oncology, vol. 24, no. 5, Article ID mds642, pp. 1211-1219, 2013.

[43] H. Harder, R. Ballinger, C. Langridge, A. Ring, and L. J. Fallowfield, "Adjuvant chemotherapy in elderly women with breast cancer: patients' perspectives on information giving and decision making," Psycho-Oncology, vol. 22, no. 12, pp. 27292735, 2013. 


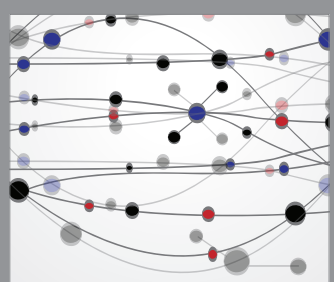

The Scientific World Journal
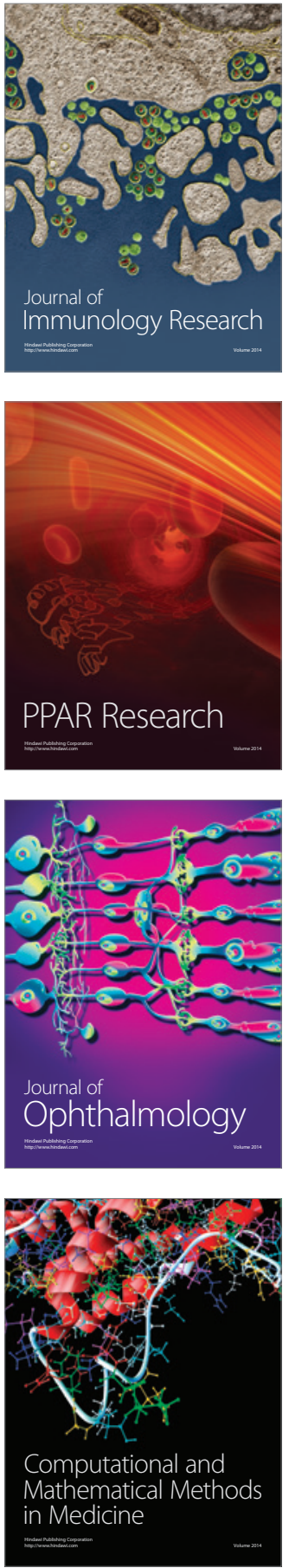

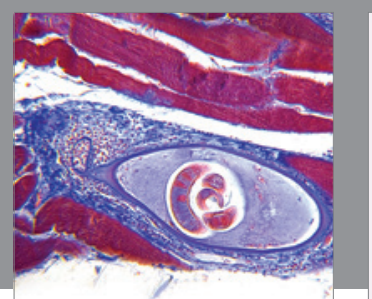

Gastroenterology Research and Practice

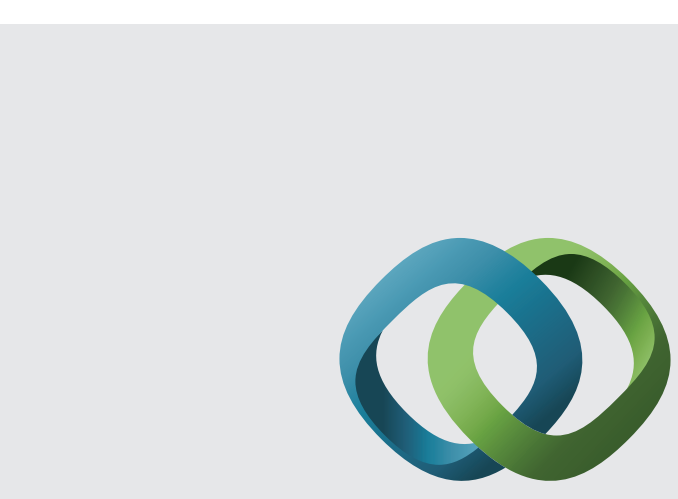

\section{Hindawi}

Submit your manuscripts at

http://www.hindawi.com
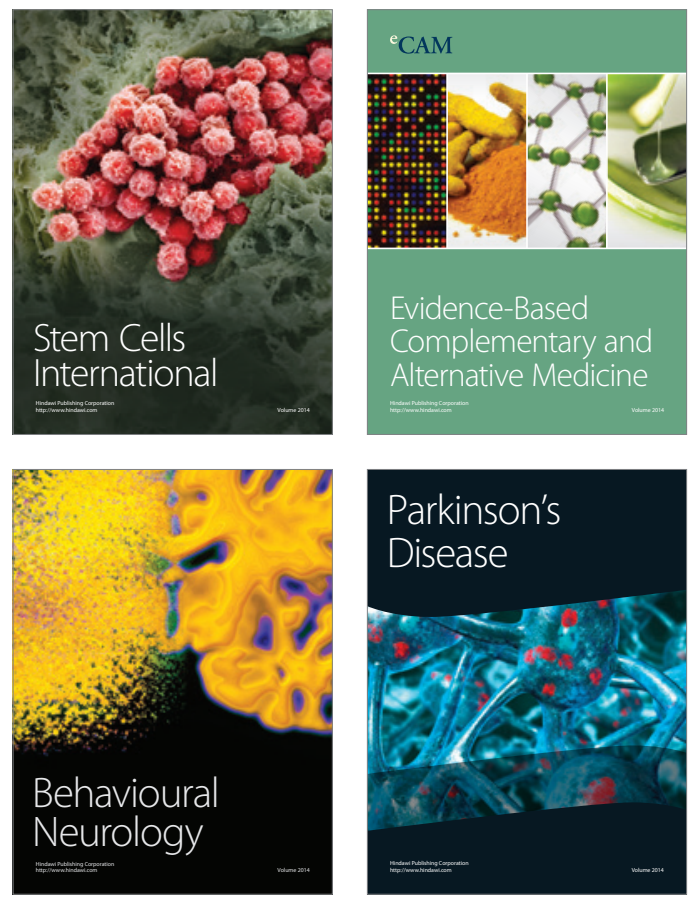
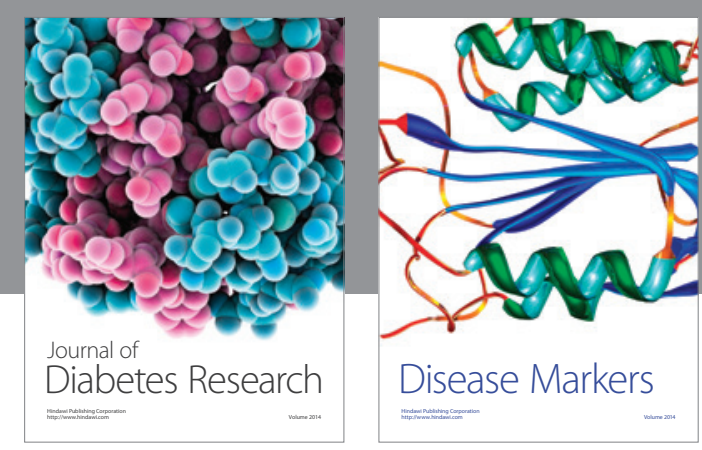

Disease Markers
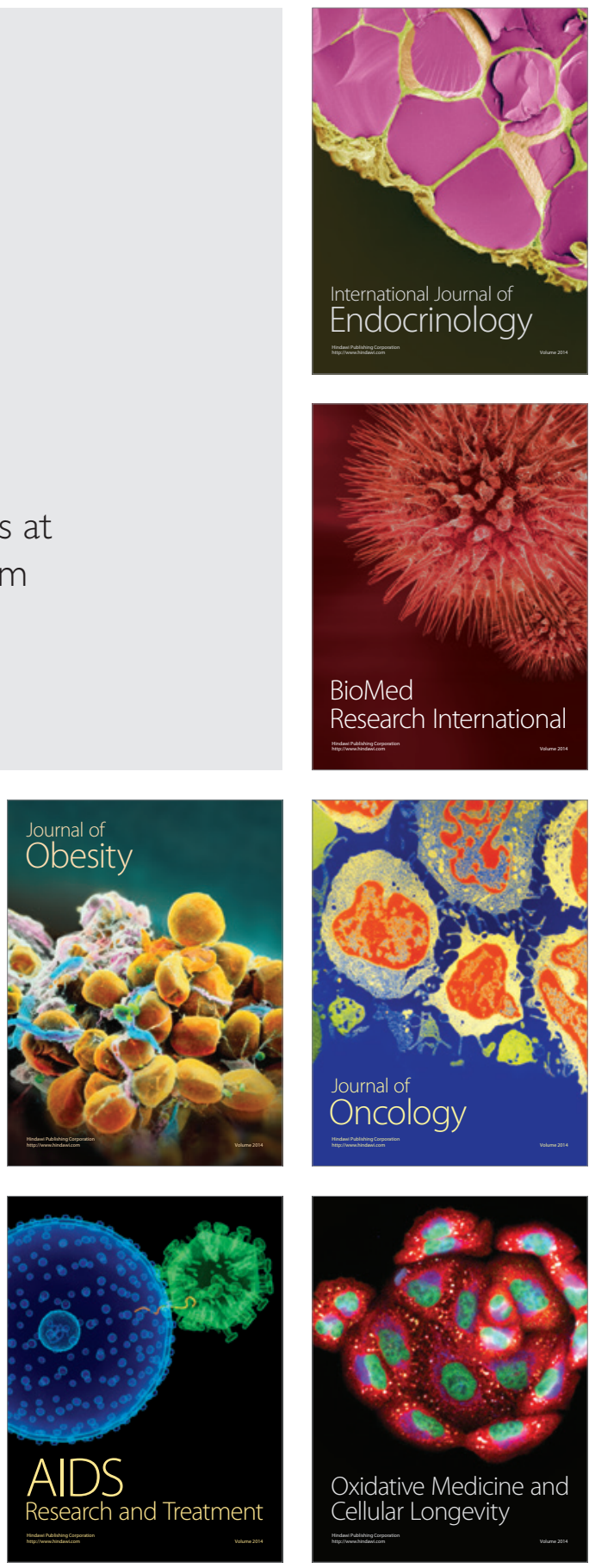